\title{
Does the private university sector exploit sustainable residential life in the name of supporting the fourth industrial revolution?
}

\begin{abstract}
Following WTO (World Trade Organisation) advice, a privatised university sector in the developing world began in the early 1990s and it grew rapidly. The purpose of establishing a private university sector was to make the education system respond to the needs of industry. In the 1990s, the anticipated technological boom would change many industries globally. Traditionally, public universities are often reluctant to welcome innovation so it was left to the private sector to welcome the challenges in regard to the fourth industrial revolution. Unfortunately, owing to a number of limitations, private universities have not fully embraced what industries want. They are mainly established in prime residential areas and therefore the core goal of private universities is redundant; there are now many 'sustainable elements' of residential life being degraded. This study investigated the impact of unplanned expansion of private sector universities on sustainable residential life adopting the qualitative method. Both primary and secondary data were used. Greenery, heat and night light intensity indexes were considered as fundamental parameters to measure 'sustainable residential life'. Findings show that rapid growth of the student population has compromised the sustainability indexes. While the greenery index has dramatically declined, heat and night light indexes have increased unexpectedly. These intensifications have impacted greatly on the concept of sustainable residential life. Conversely, the private university sector does not necessarily produce the skilled manpower needed by various industries to solve the challenges that characterise the fourth industrial revolution. Yet the residential areas have great potential as commercially vibrant places in which sustainable residential and academic life can co-exist. An integrated policy framework is suggested to improve this situation.
\end{abstract}

Keyword: Fourth industrial revolution; University and industrial development; University and city; Sustainability in residential life; University and climate change; Private University 